\title{
Key Features of Personalized Learning
}

\author{
Dr. Salian Çullhaj
}

German Department, University of Tirana, Faculty of Foreign Languages, Albania

\begin{abstract}
The term personalized learning, or personalization, refers to a diverse variety of educational programs, learning experiences, instructional approaches, and academic-support strategies that are intended to address the distinct learning needs, interests, aspirations, or cultural backgrounds of individual students.
\end{abstract}

Keywords: Key Features of Personalized Learning

\section{Introduction}

According to the National Educational Technology Plan developed by the US Department of Education, personalized learning means adjusting the pace (individualization), adjusting the approach (differentiation), and connecting to the learner's interests and experiences. Personalization, in theory, is broader than mere individualization or differentiation in that it affords the learner a degree of choice about learning. ${ }^{1}$

The International Association for K-12 Online Learning (iNACOL) defines personalized learning as "tailoring learning for each student's strengths, needs, and interests-including enabling student voice and choice in what, how, when, and where they learn-to provide flexibility and supports to ensure mastery of the highest standards possible."

\section{What are key features of personalized learning?}

Based on web researched information, there are 4 key elements that form effective personalized learning practices.

\section{Learner Profiles}

Within the personalized learning environment, emphasis is placed on understanding each and every student. Learner profiles offer deep insights into "each student's individual strengths, needs, motivations, progress, and goals", in an effort to provide the best possible solutions. Adaptive systems provide learner profiles tailored to the individual that add to each student's Learning DNA. These personalized profiles provide portals for educators to get to know every single student on a personal level, with the system providing resources tailored to each one.

\section{Personalized Learning Paths}

With personalized learning paths, "each student follows a customized path that responds and adapts based on his or her learning progress, motivations, and goals." This allows students to engage in independent learning, through a tailored learning experience. Fishtree ${ }^{3}$ identifies personalized learning paths for each student, offering tailored resources along the way, with consistent support guiding them towards mastery of each objective. Each path is clearly identifiable by students and teacher, offering a deeper understanding of progress and performance.

\section{Competency-Based Progression}

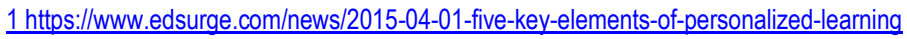

2 http://fishtreeblog.tumblr.com/post/105439362855/the-4-biggest-features-of-personalized-learning\#sthash.uG7Q7P9x.dpuf

${ }^{3}$ http://www.inacol.org/resources/resource-search/?resource topics $=18$ 
Competency-based progression involves a process whereby "each student's progress toward clearly defined goals is continually assessed." This ensures mastery of skills and competencies as students progress upon demonstration of proficiency, as opposed to measurement of seat time.

\section{Flexible Learning Environment}

Within personalized learning practices, "student needs drive the design of the learning environment." With this in mind, the learning process rotates around students reaching their goals according to their own pace, needs, and interests. Adaptive platforms ensure a flexible approach that works around students with a mobile system that offers tailored resources and assessments. Educators are then free to adjust teaching methods to incorporate flipped, blended and mobile learning to meet the needs of every student. Combining all four key ingredients, the personalized learning environment is proven to be increasingly productive for both students and teachers.

Another essential element of personalized learning, based on iNACOL's ${ }^{1}$ discussions with educators in the field is:

Student Agency: Students should have some control over how they learn. With the help of their teachers, they should be involved in designing their own learning process and should be given a choice in how to demonstrate their learning through performance-based assessments.

Below is a visual representation of the four core features including Student Agency as a fifth one.

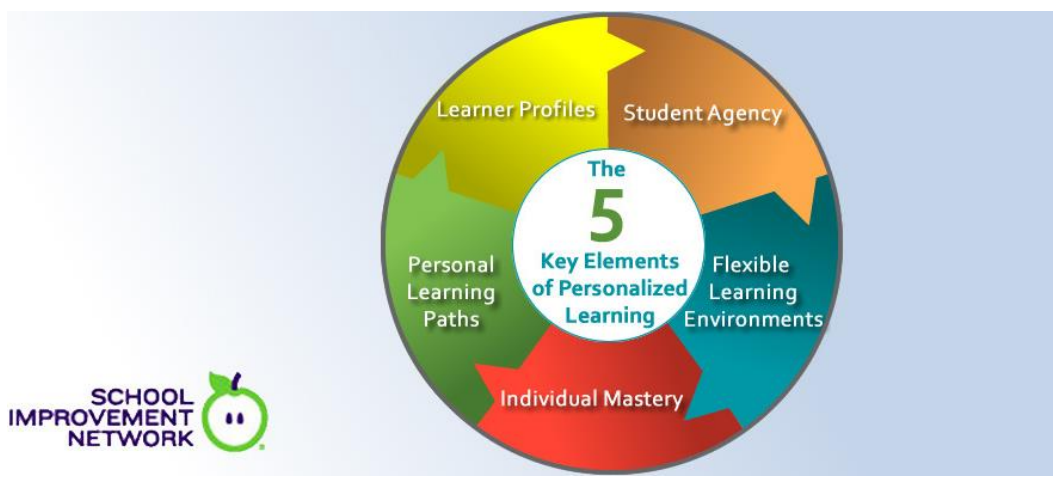

Source: https://www.edsurge.com/news/2015-04-01-five-key-elements-of-personalized-learning

\section{What Personalized Learning really means and why there is value? Background}

The idea of personalized learning is as old as time itself. The instructional model in which a tutor instructs an individual student one-on-one has long been accepted as the most effective method of educating a student. As tutors are able to adjust the pace of learning to the specific needs of their individual student, the power of personalized learning has proved not only to make intuitive sense, but has been supported by research as well. Benjamin Bloom's 1984 study, for example, showed that students who were tutored 1-on-1 performed much better than those who received standard classroom instruction (Bloom, 1984; Horn, 2014).

Based on 2013 article titled The Next Generation of (Personalized) Learning, Stacey Childress and Scott Benson at Bill \& Melinda Gates Foundation debate that "For more than 150 years, the system has been organized around the idea that students of similar ages should move along together, through the same material, at roughly the same pace". 2

In recent years, the idea of personalized learning has become a new focus for many districts and a trendy buzzword for anyone and everyone involved in the field of education.

\footnotetext{
1 http://www.impatientoptimists.org/Posts/2013/01/The-Next-Generation-of-Personalized-Learning\#.V8XpHk14cuU

2 In this work we talk about intelligence in terms of information as opportunity or possibility, that is, knowledge structures that, being contextually relevant, allow an advantageous intervention in reality (to be succesful). Thus, it refers to the set of integrated capabilities as a unit: learning, feeling, incorporating, linking, experiencing and communicating.
} 
Having a closer look at our country's history, America is called a melting pot for many reasons. Each individual carries unique traits: culture, family, learning styles, interests, skills, life experiences, and more. We're all at our best when we can tap into those characteristics that make us unique. That's especially true when it comes to education.

A single dad looking to earn a college degree while raising an infant may need a flexible learning environment that allows him to learn at his own pace-and on his own schedule. A high school senior who hates physics, but loves skateboarding, might need a trip to the skate park to better understand speed, velocity, and momentum. Learning becomes even more powerful when it's personalized to each student's needs, interests, and circumstances.

\section{Current status of Professional Learning application}

The Debate around the new trend

\section{Organizations engaged and resources}

Other related Resources and Articles:

\section{Personalized Learning}

http://k12education.gatesfoundation.org/student-success/personalized-learning/

\section{5 things you should know about Personalized Learning}

http://www.impatientoptimists.org/Posts/2014/11/5-Things-You-Should-Know-About-PersonalizedLearning\#.V8XVjU14cuU

\section{The Next Generation of (Personalized) Learning}

http:/www.impatientoptimists.org/Posts/2013/01/The-Next-Generation-of-Personalized-Learning\#.V8XpHk14cuU

Four Reasons to Worry About "Personalized Learning" by Alfie Kohn https://www.psychologytoday.com/blog/thehomework-myth/201502/four-reasons-worry-about-personalized-learning

Updated Personalization vs. Differentiation vs. Individualization Chart Version 3

http://www.personalizelearning.com/2013/03/new-personalization-vs-differentiation.html 